\title{
Unraveling the kinetic diversity of microbial 3-dehydroquinate dehydratases of shikimate pathway
}

Chang Liu ${ }^{1,2}$, Yi-Ming Liü ${ }^{1,2}$, Qing-Lan Sun ${ }^{3}$, Cheng-Ying Jiang ${ }^{1,2}$ and Shuang-Jiang Liu ${ }^{1,2^{*}}$

\begin{abstract}
3-Dehydroquinate dehydratase (DHQase) catalyzes the conversion of 3-dehydroquinic acid to 3-dehydroshikimic acid of the shikimate pathway. In this study, 3180 prokaryotic genomes were examined and 459 DHQase sequences were retrieved. Based on sequence analysis and their original hosts, 38 DHQase genes were selected for chemical synthesis. The selected DHQases were translated into new DNA sequences according to the genetic codon usage bias by both Escherichia coli and Corynebacterium glutamicum. The new DNA sequences were customized for synthetic biological applications by adding Biobrick adapters at both ends and by removal of any related restriction endonuclease sites. The customized DHQase genes were successfully expressed in E. coli, and functional DHQases were obtained. Kinetic parameters of $K_{m}, k_{c a t}$ and $V_{\max }$ of DHQases were determined with a newly established high-throughput method for DHQase activity assay. Results showed that DHQases possessed broad strength of substrate affinities and catalytic capacities. In addition to the DHQase kinetic diversities, this study generated a DHQase library with known catalytic constants that could be applied to design artificial modules of shikimate pathway for metabolic engineering and synthetic biology.
\end{abstract}

Keywords: 3-Dehydroquinate dehydratase (DHQase); Kinetic constants; Shikimate pathway; Biobrick; Synthetic biology

\section{Introduction}

Shikimate pathway widely exists in microbes and plants, but not animals. This pathway is involved in the synthesis of aromatic amino acids, vitamins, as well as lignin (Herrmann and Weaver 1999; Vanholme et al. 2012). The pathway consists of seven catalytic steps, condensing erythrose-4-phosphate (E4P) and phosphoenolpyruvate (PEP) finally into chorismate. 3-Dehydroquinate dehydratase (DHQase, EC 4.2.1.10) catalyzes the third step, i.e., reversible transformation of DHQ to form 3dehydroshikimic acid. DHQases belong to the family of lyases, and cleave carbon-oxygen bonds. So far as known, DHQases involve in not only shikimate pathway but also other metabolic processes such as the quinate pathway for synthesis of 4-hydroxybenzoic acid (Giles

\footnotetext{
* Correspondence: liusj@im.ac.cn

${ }^{1}$ State Key Laboratory of Microbial Resources, Chinese Academy of Sciences, Beijing 100101, China

Environmental Microbiology Research Center, Chinese Academy of Sciences, Beijing 100101, China

Full list of author information is available at the end of the article
}

et al. 1985; Giles et al. 1991). According to their origins and catalytic features, DHQases are classified into either type I or type II. Type I DHQases are heat-liable dimeric (Roszak et al. 2002), and mainly occur in plants and fungi. Type II DHQases are heat-stable dodecameric (Roszak et al. 2002) and widely occur in bacteria for shikimate pathway or in fungi for quinate catabolism (Giles et al. 1991).

Many investigations of DHQases have been focused on their structures and catalytic mechanisms (Blomberg et al. 2009; Bottomley et al. 1996; Devi et al. 2013; Lee et al. 2002; Pan et al. 2012; Roszak et al. 2002), or on structure-based design of inhibitors to DHQase activity (Blanco et al. 2012; 2014; Dias et al. 2011; Peon et al. 2010). These investigations have generated increasing numbers of DHQase structures with high resolution and have significantly advanced the understanding of DHQase catalytic mechanisms (Chaudhuri et al. 1986; Deka et al. 1994; Euverink et al. 1992; Hawkins et al. 1993; Lee et al. 2003; Moore et al. 1993; Roszak et al. 
2002; Singh and Christendat 2006). Type I DHQases catalyze the dehydrogenation of DHQ through a ciselimination (Chaudhuri et al. 1991; Gourley et al. 1999; Leech et al. 1995), while type II DHQases take a transelimination mechanism (Blomberg et al. 2009; Bottomley et al. 1996).

Recent study has revealed that overexpression of DHQase enhanced transformation of quinic acid into shikimic acid in Gluconobacter oxydans (Nishikura-Imamura et al. 2014). The kinetic properties of DHQases such as $\mathrm{K}_{\mathrm{m}}, \mathrm{V}_{\max }$, and $\mathrm{k}_{\mathrm{cat}}$ are important particularly to design new biocatalysts and to predict the validity and efficiency of newly constructed metabolic networks. So far, only a small number of DHQases from prokaryotes such as Escherichia coli, Mycobacterium tuberculosis, and Streptomyces coelicolor were characterized for their catalytic properties (Harris et al. 1996; Kleanthous et al. 1992; Moore et al. 1993; Richards et al. 2006; White et al. 1990), and the catalytic and kinetic properties of the majority of microbial DHQases remain still unknown.

In this study, we aimed to investigate the kinetic diversities of DHQases and to expand the toolbox of catalytic parts for synthetic biology. By data-mining of 3180 prokaryotic genomes from NCBI genome database, $459 \mathrm{pu}-$ tative DHQases were targeted. Thirty-eight DHQases were further selected and standardized according to "Biobricks" requirements (Knight 2003; Shetty et al. 2011; Sleight et al. 2010). DHQase kinetic constants were determined with a newly established high-throughput method. Our results showed that DHQases are highly diverse in catalytic kinetics.

\section{Materials and methods}

\section{Genome data-mining for DHQase genes}

The amino acid sequences of the type II DHQase (NP_599670) from Corynebacterium glutamicum ATCC13032 and of the type I DHQase (NP_416208) from E. coli $\mathrm{K}-12$ were used as seed sequences to retrieve putative DHQase sequences from NCBI genome database with a filter condition of threshold $E$ value $\leq 10^{-10}$. The retrieved sequences were then screened and redundant copies were removed. To increase the credibility of functional DHQase prediction, the retrieved sequences were further filtered by removal of putative DHQase sequences from which host organisms have incomplete shikimate pathway in their genomes.

\section{Design and chemical synthesis of DHQase genes}

The selected DHQase amino acid sequences were reversetranslated into DNA sequences, and were recoded with referring codon usage bias of E. coli and C. glutamicum. The obtained DNA sequences were optimized for expression in E. coli and C. glutamicum by check for RNA secondary structure with software UNAFold (Markham and
Zuker 2008). Any predicted secondary structures were eliminated by codon replacements. The new DHQase genes were further customized, by linking to Biobrick adapters (Knight 2003) at both ends. The customized DNA sequences of the DHQases are accessible at http:// www.genoportal.org/bbdb/ under the accession numbers of SBB_00477 SBB_004481, and were chemically synthesized (Sangon Biotech, China), and were cloned in E. coli. The DNA sequences of the chemically synthesized DHQase genes were confirmed by DNA sequencing.

\section{Bacterial strain, plasmids, and growth condition}

For cloning and expression of DHQase genes, E. coli BL21 (DE3) (TransGen Biotech, China) and plasmid $\mathrm{pET}^{28 \mathrm{a}^{+}}$(Novagen, Germany) were used. Expression of DHQase genes was induced with $0.1 \mathrm{mmol} / \mathrm{L}$ of IPTG when culture reached $\mathrm{OD}_{600 \mathrm{~nm}}$ of 0.6-0.8. After addition of IPTG, culture was further incubated at $16^{\circ} \mathrm{C}$, overnight. Routine cultivation of $E$. coli proceeded in LuriaBertani (LB) medium at $37^{\circ} \mathrm{C}$ and at $200 \mathrm{rpm}$ rotatory shaking. To maintain the stability of pET28a ${ }^{+}$and its derivatives, kanamycin at final concentration of $100 \mu \mathrm{g} / \mathrm{ml}$ were added into LB medium.

\section{Preparation of cellular lysates and purification of DHQase proteins}

E. coli cells were harvested by centrifugation at 10,000 rpm, and suspended in $50 \mathrm{mmol} / \mathrm{L}$ Tris- $\mathrm{HCl}$ buffer, $\mathrm{pH}$ 8.0. After addition of $0.01 \%(\mathrm{w} / \mathrm{v})$ protease inhibitor cocktail (Amresco, the United States), cell suspension was treated with ultrasonication (work for $3 \mathrm{sec}$, stop for $5 \mathrm{sec}, 100$ repeats). The cellular debris was removed by centrifugation at 10,000 rpm for $10 \mathrm{~min}$, and the supernatant was filtered with $0.22 \mu \mathrm{m}$ filters (Millipore, the United States). The filtered supernatant was collected and DHQase proteins were purified using HisPur ${ }^{\mathrm{rm}} \mathrm{Ni}$ NTA Spin Columns Kit (Thermo Scientific, the United States). The purified DHQase proteins were stored at $-80^{\circ} \mathrm{C}$ in $50 \mathrm{mmol} / \mathrm{L}$ Tris- $\mathrm{HCl}(\mathrm{pH} 8.0)$ buffer containing $25 \%$ glycerol. All procedures were operated at $4^{\circ} \mathrm{C}$ unless indicated.

Protein concentrations were determined with Bio-Rad Protein Assay (BIO-RAD, the UK).

Tricine sodium dodecyl sulfate polyacrylamide gel electrophoresis was used to evaluate the DHQase expression and the purity during protein purification. Preparation of gels (4\% sample gel and 10\% separating gel) and operation of electrophoresis were conducted according to Schägger (2006). Gels were visualized with Coomassie brilliant blue G-250 staining, and were scanned with PC scanner (T68, Founder, China) for imagine analysis. 
Table 1 Distribution of type I and type II DHQases in prokaryotic genomes ${ }^{a}$

\begin{tabular}{lll}
\hline Sources & DHQase in a genome & Number of genomes \\
\hline Bacteria & Type I only & 60 \\
& Type II only & 306 \\
& Both Type I and II & 25 \\
Archaea & Type I & 43 \\
\hline
\end{tabular}

${ }^{a}$ Notes: Redundant genomes representing the same species were removed.

\section{DHQase activity assays}

A high-throughput method of DHQase activity assay was established in this study. The method has the same principal for measurement as White et al. (1990), but with new systems. Synergy H4 Hybrid Multi-Mode Microplate Reader (BioTek, the UK) and 96 Well UV-Plate (Corning Costar, the United States) were used to monitor the changes of $\mathrm{OD}_{234 \mathrm{~nm}}$ of multi-samples. DHQase catalysis was optimized in volume of $100 \mu \mathrm{L}$ and with various DHQ concentrations (0.08 to $1.0 \mathrm{mmol} / \mathrm{L}$ ). Kinetic constants $\mathrm{K}_{\mathrm{m}}$ and $\mathrm{V}_{\max }$ were calculated according to Lineweaver-Burk plot.

\section{Sequence alignments and construction of phylogenetic tree}

The amino acid sequences of DHQases were retrieved from NCBI genome database. Amino acid sequence alignment of DHQases were performed with MUSCLE (Edgar 2004), and the graphic display of alignments were made by ESPript3.0 (Gouet et al. 1999). The phylogenetic tree of amino acid sequences from all putative DHQases were firstly constructed by Phylip Package (Abdennadher and Boesch 2007) under Linux system with method of maximum likelihood and bootstrap replications of 1000, and further annotated using iTOL v2.2.2 (Letunic and Bork 2011).

\section{Results}

\section{DHQases are phylogenetically diverse}

3180 genomes were explored for putative DHQases, and 459 putative DHQase were targeted, including 128 type I and 331 type II DHQases. Noticeably, all archaeal DHQases were type I. Bacterial genomes carried both type I and type II DHQases, which $79.6 \%$ of the bacterial DHQases were type II and 20.4\% were type I. Of the 391

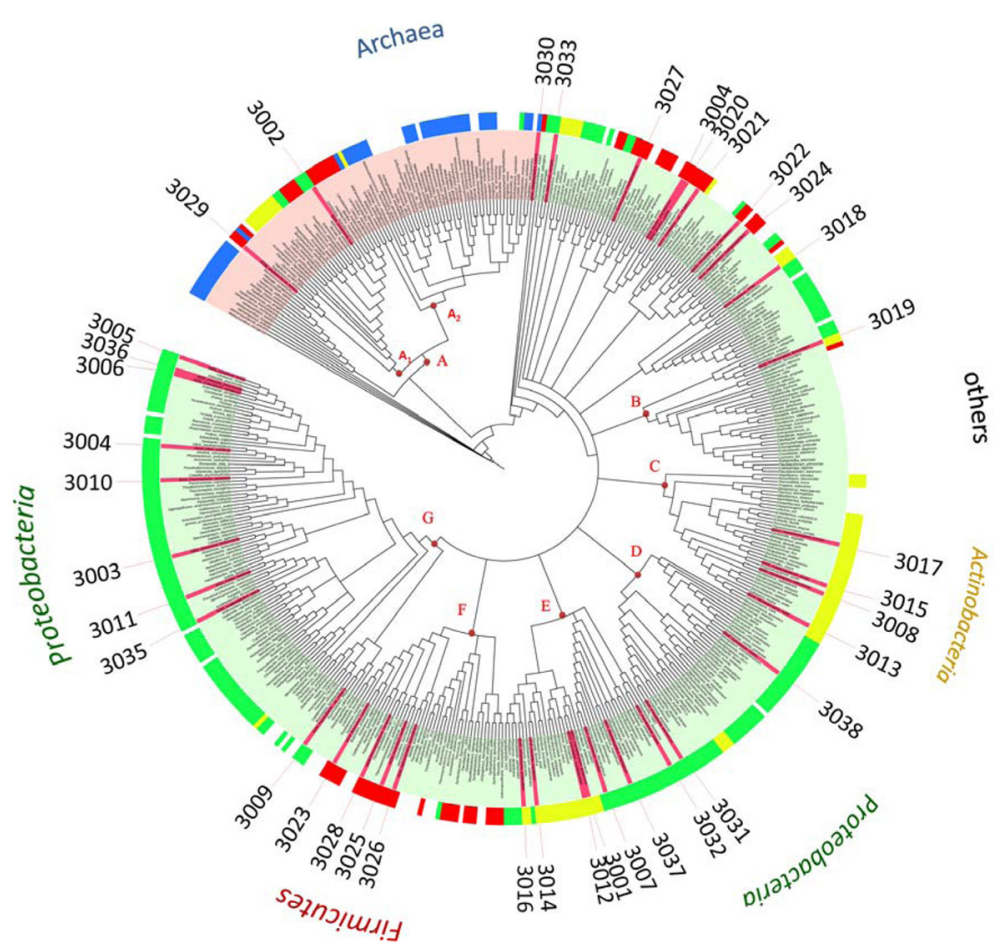

Figure 1 Circle phylogenetic tree of 459 DHQases, constructed with Maximum Likelihood method with 1000 bootstrap replications. The salmon color range covers all species with type I DHQases, the light green range covers all species with type II DHQases. The codes for the 38 selected DHQases were assigned outside circles. For the outmost color ring, colored strips indicate the origins (at phylum levels) of the DHQases: Firmicutes is marked with red strips, Proteobacteria is green, Actinobacteria is yellow. All archaea including Thaumarchaeota, Crenarchaeota, and Euryarchaeota are showed in dark blue. Species from other phylum is left with no color strips. Capital letters A-G indicated7 big clades with bootstrap support values $>70 \%$. 
Table 2 Selected DHQase, their origins and theoretical molecular masses of translational products

\begin{tabular}{|c|c|c|c|c|c|}
\hline $\begin{array}{l}\text { Codes for } \\
\text { DHQases }^{\mathrm{a}} \\
\end{array}$ & Origins & $\begin{array}{l}\text { NCBI accession } \\
\text { numbers of }\end{array}$ & $\begin{array}{l}\text { Accession IDs at www. } \\
\text { genoportal.org }\end{array}$ & $\begin{array}{l}\text { Theoretical molecular } \\
\text { mass }(\mathrm{kDa})\end{array}$ & $\begin{array}{l}\text { Sequence } \\
\text { identity }\end{array}$ \\
\hline \multicolumn{6}{|l|}{ Type I } \\
\hline 3002 & Escherichia coli & YP_489955.1 & SBB_00449 & 27.5 & $100 \%$ \\
\hline 3029 & Staphylococcus aureus & YP_005744190.1 & SBB_00476 & 26.9 & $30.0 \%$ \\
\hline 3030 & Metallosphaera cuprina & YP_004409005.1 & SBB_00477 & 23.7 & $23.5 \%$ \\
\hline \multicolumn{6}{|l|}{ Type II } \\
\hline 3001 & Corynebacteriumglutamicum & YP_224725.1 & SBB_00448 & 15.4 & $100.0 \%$ \\
\hline 3003 & Alcanivorax borkumensis & YP_693728.1 & SBB_00450 & 17.5 & $50.7 \%$ \\
\hline 3004 & Bacillus pseudofirmus & YP_003425282.1 & SBB_00451 & 16.5 & $50.0 \%$ \\
\hline 3005 & Citrobacter koseri & YP_001456151.1 & SBB_00452 & 16.5 & $53.4 \%$ \\
\hline 3006 & Enterobacter aerogenes & YP_004591144.1 & SBB_00453 & 16.5 & $53.0 \%$ \\
\hline 3007 & Gluconobacter oxydans & YP_190876.1 & SBB_00454 & 17.4 & $51.1 \%$ \\
\hline 3008 & Mycobacterium tuberculosis & YP_003031384.1 & SBB_00455 & 15.8 & $52.6 \%$ \\
\hline 3009 & Psychrobactersp. PRwf-1 & YP_001279670.1 & SBB_00456 & 18.4 & $52.8 \%$ \\
\hline 3010 & Psychromonas ingrahamii & YP_944417.1 & SBB_00457 & 16.5 & $53.0 \%$ \\
\hline 3011 & Xylella fastidiosa & NP_297340.2 & SBB_00458 & 16.7 & $52.2 \%$ \\
\hline 3012 & Arthrobacter crystallopoietes & EMY34512.1 & SBB_00459 & 16.3 & $71.9 \%$ \\
\hline 3013 & Micromonas poralupini & $\mathrm{CCH} 17589.1$ & SBB_00460 & 15.4 & $47.8 \%$ \\
\hline 3014 & Nocardia brasiliensis & YP_006813099.1 & SBB_00461 & 15.6 & $64.0 \%$ \\
\hline 3015 & Propionibacterium acnes & YP_056375.1 & SBB_00462 & 15.8 & $43.7 \%$ \\
\hline 3016 & Streptomyces acidiscabies & WP_010352491.1 & SBB_00463 & 16.8 & $61.4 \%$ \\
\hline 3017 & Thermomonas poracurvata & YP_003300530.1 & SBB_00464 & 16.6 & $45.3 \%$ \\
\hline 3018 & Atopobium rimae & EEE18006.1 & SBB_00465 & 15.5 & $41.7 \%$ \\
\hline 3019 & Acidimicrobium ferrooxidans & YP_003110305.1 & SBB_00466 & 16.4 & $45.8 \%$ \\
\hline 3020 & Bacillus subtilis & NP_390327.1 & SBB_00467 & 16.4 & $49.3 \%$ \\
\hline 3021 & Geobacillus sp. Y4.1MC1 & YP_003988579.1 & SBB_00468 & 16.0 & $48.6 \%$ \\
\hline 3022 & $\begin{array}{l}\text { Alicyclobacillus } \\
\text { acidocaldarius }\end{array}$ & EED07485.1 & SBB_00469 & 16.3 & $49.6 \%$ \\
\hline 3023 & Butyrivibrio crossotus & EFF68279.1 & SBB_00470 & 22.8 & $47.1 \%$ \\
\hline 3024 & $\begin{array}{l}\text { Halanaerobium } \\
\text { hydrogeniformans }\end{array}$ & YP_003995185.1 & SBB_00471 & 16.6 & $51.4 \%$ \\
\hline 3025 & Clostridium clariflavum & YP_005045936.1 & SBB_00472 & 15.5 & $53.1 \%$ \\
\hline 3026 & $\begin{array}{l}\text { Natranaerobius } \\
\text { thermophilus }\end{array}$ & YP_001917881.1 & SBB_00473 & 15.8 & $43.7 \%$ \\
\hline 3027 & $\begin{array}{l}\text { Ruminococcus } \\
\text { champanellensis }\end{array}$ & YP_007829441.1 & SBB_00474 & 16.1 & $49.6 \%$ \\
\hline 3028 & $\begin{array}{l}\text { Thermodesulfobium } \\
\text { narugense }\end{array}$ & YP_004438087.1 & SBB_00475 & 16.8 & $46.3 \%$ \\
\hline 3031 & Comamonas testosteroni & YP_003279351.1 & SBB_00478 & 15.9 & $52.1 \%$ \\
\hline 3032 & Pseudomonas putida & NP_745147.1 & SBB_00479 & 16.2 & $59.4 \%$ \\
\hline 3033 & Halomonas elongata & YP_003899044.1 & SBB_00480 & 15.5 & $55.8 \%$ \\
\hline 3034 & Vibrio vulnificus & NP_935927.1 & SBB_00481 & 18.7 & $55.6 \%$ \\
\hline 3035 & Acidithiobacillus caldus & YP_004750222.1 & SBB_00482 & 16.9 & $50.7 \%$ \\
\hline
\end{tabular}


Table 2 Selected DHQase, their origins and theoretical molecular masses of translational products (Continued)

\begin{tabular}{|c|c|c|c|c|c|}
\hline 3036 & Klebsiella pneumoniae & EMH96211.1 & SBB_00483 & 16.5 & $51.5 \%$ \\
\hline 3037 & $\begin{array}{l}\text { Magnetospirillum } \\
\text { magneticum }\end{array}$ & YP_422069.1 & SBB_00484 & 14.5 & $50.4 \%$ \\
\hline 3038 & Zymomonas mobilis & YP_162472.1 & SBB_00485 & 15.8 & $52.9 \%$ \\
\hline
\end{tabular}

The amino acid sequence identities of DHQases to the one from C. glutamicum (type II) or from E. coli (type I) were calculated based on alignment with BLAST searches. The NCBI numbers refer to the wildtype DHQases, and the customized DNA sequences of these DHQases are accessible at http://www.genoportal.org/bbdb. ${ }^{a}$ The first digit of the code represents DHQase catalyzes the 3rd step of shikimate pathway, and the following digits are the order when that DHQases were selected.

genomes explored, 306 genomes (78.3\%) harbored only type II DHQases, 60 genomes (15.3\%) harbored only type I, and 25 genomes (6.4\%) harbored both type I and type II (Table 1).

To display the phylogenetic relationship of all 459 DHQase sequences and taxonomic distribution, their amino acid sequences were used to construct a phylogenetic tree (Figure 1). As seen from Figure 1, seven clades (from cluster A to G) of DHQases were recognized. The majority of type I DHQases fell into the clade A, which contained two sub-clades $\mathrm{A}_{1}$ and $\mathrm{A}_{2}$. Sub-clade $\mathrm{A}_{1}$ covered bacterial type I DHQases from Proteobacteria, Actinobacteria, and Firmicutes. Sub-clade $\mathrm{A}_{2}$ was mainly archaeal DHQases from Thaumarchaeota, Crenarchaeota, and Euryarchaeota. Clades B through G was type II DHQases of different bacterial phyla. DHQases of the clades $\mathrm{C}$ and $\mathrm{F}$ were mainly from Actinobacteria and Firmicutes, respectively. DHQases of clades D and G were mainly from Proteobacteria. DHQases of clades B and E were from Proteobacteria, Actinobacteria and other bacterial phyla.

\section{Cloning and expression of customized DHQase genes in E. coli cells}

From all retrieved 459 DHQases, 38 were further selected (Table 2).The selection was carried out according to the following criterions: 1) Both type I and type II DHQases were included, and the majority was bacterial type II DHQases; 2) Host genomes harbored a complete shikimate pathway, or taxonomically representative ( $A r$ chaea, Actinobacteria, Firmicutes, and Proteobacteria), or from unique habitats. From the 38 DHQases, 35 were of type II, and 3 were of type I. The theoretical molecular masses of type II DHQases were ranged from 15 to $18 \mathrm{kDa}$, and their amino acid sequence identities to DHQase from C. glutamicum were 41.7-71.9\%. The selected DHQases were recorded by referring the codon usages of E. coli and of C. glutamicum (Nakamura 2007). The new DNA sequences were edited by curing restriction endonucleases (NdeI, XhoI, EcoRI, NotI, XbaI, SpeI and PstI) sites and any predicted secondary mRNA structures. Further, the sequences were customized for "Biobricks" (Knight 2003) by attaching the prefix5'GCAGAATTCGCGGCCGCTTCTAGA-3' and the suffix 5' -ACTAGTAGCGGCCGCCTGCAG-3'.
All 38 DHQase genes were cloned with E. coli. Except those DHQases of A. ferrooxidans, B. pseudofirmus, $S$. aureus and $Z$. mobilis that occurred as either inclusion bodies or no synthesis in E. coli cells, all other DHQase were synthesized and purified. The purified DHQases actively catalyzed the conversion of DHQ into 3-dehydroshikimic acid.

\section{DHQases have broad ranges of kinetic parameters}

Catalytic properties such as $\mathrm{V}_{\max }, \mathrm{K}_{\mathrm{m}}, \mathrm{k}_{\text {cat }}$, and $\mathrm{k}_{\mathrm{cat}} / \mathrm{K}_{\mathrm{m}}$ of the selected DHQases were determined and are listed in Table 3. Results showed that their kinetic parameters are distributed in broad ranges, which suggested a kinetic diversity of DHQases regarding catalytic capacity and efficiency, and substrate affinity. The $\mathrm{V}_{\max }$ values of DHQases at the given enzyme concentrations in this study were determined to be 0.57-66.7 $\mu \mathrm{mol} / \mathrm{L} / \mathrm{s}$. The $\mathrm{K}_{\mathrm{m}}$ values were determined to be $37.2-2226.5 \mu \mathrm{mol} / \mathrm{L}$. These results indicated that natural DHQases had evolved broad catalytic properties, probably for reasons to serve their hosts at different growing conditions. The DHQase (Code 3012) from A. crystallopoietes showed the highest catalytic capacity $\left(\mathrm{V}_{\max }=66.7 \mu \mathrm{mol} / \mathrm{L} / \mathrm{s}\right)$ and moderate affinity to 3-dehydroquinate $\left(\mathrm{K}_{\mathrm{m}}=\right.$ $448.5 \mu \mathrm{mol} / \mathrm{L}$ ). The DHQase (Code 3031) from C. testosteroni showed highest affinity to 3-dehydroquinate $\left(K_{m}=37.2 \mu \mathrm{mol} / \mathrm{L}\right)$ among the tested DHQases. The kinetic parameter $\mathrm{k}_{\text {cat }}$ signifying the catalytic efficiency of an enzyme, and it was found that the DHQase (Code 3016) from $S$. acidiscabies was the most efficient one among the tested DHQases and its $\mathrm{k}_{\text {cat }}$ value was determined to be $211.83 \mathrm{~s}^{-1}$. When all the tested DHQases were evaluated by $\mathrm{k}_{\text {cat }} / \mathrm{K}_{\mathrm{m}}$ values, the DHQase (Code 3016) had the highest $\mathrm{k}_{\mathrm{cat}} / \mathrm{K}_{\mathrm{m}}$ value $(1.50 \mathrm{~L} / \mu \mathrm{mol} / \mathrm{s})$ that represented the best catalytic specificity and efficiency among all the tested DHQases. In addition, the specific activities of DHQases at 3-dehydroquniate concentration of $0.5 \mathrm{mM}$ were determined and DHQase (Code 3016) from S. acdiscabies showed the highest activity (501.87 units/mg). Figure 2 depicts a whole image of kinetic parameter distribution of DHQases. Apparently, the kinetic parameters of all tested DHQases varied significantly, reflecting a long-span distribution of their catalytic properties and kinetic diversity. 
Table 3 The kinetic parameters of 3-dehydroquinate dehydratases

\begin{tabular}{|c|c|c|c|c|c|}
\hline Codes for DHQases* & $\mathrm{V}_{\max }(\mu \mathrm{mol} / \mathrm{L} / \mathrm{s})$ & $\mathrm{K}_{\mathrm{m}}(\mu \mathrm{mol} / \mathrm{L})$ & $\mathbf{k}_{\text {cat }}\left(\mathrm{s}^{-1}\right)$ & $\mathrm{k}_{\mathrm{cat}} / \mathrm{K}_{\mathrm{m}}(\mathrm{L} / \mathrm{\mu mol} / \mathrm{s})$ & Specific Activity** (U/mg) \\
\hline 3001 & 2.56 & 281.43 & 52.26 & 0.19 & 119.14 \\
\hline 3002 & 4.57 & 187.68 & 29.53 & 0.16 & 57.34 \\
\hline 3003 & 1.34 & 210.71 & 13.53 & 0.06 & 34.72 \\
\hline 3004 & - - & -— & - & - - & - \\
\hline 3005 & 15.50 & 870.37 & 208.96 & 0.24 & 93.91 \\
\hline 3006 & 6.39 & 478.67 & 102.15 & 0.21 & 187.69 \\
\hline 3007 & 2.43 & 777.75 & 77.06 & 0.10 & 84.95 \\
\hline 3008 & 2.46 & 624.52 & 23.96 & 0.04 & 46.37 \\
\hline 3009 & 4.24 & 203.24 & 31.67 & 0.16 & 75.06 \\
\hline 3010 & 0.80 & 202.55 & 10.59 & 0.05 & 9.39 \\
\hline 3011 & 0.57 & 158.79 & 7.15 & 0.05 & 15.06 \\
\hline 3012 & 66.67 & 448.50 & 185.43 & 0.41 & 369.99 \\
\hline 3013 & 7.04 & 159.89 & 4.63 & 0.03 & 86.50 \\
\hline 3014 & 3.60 & 151.51 & 3.83 & 0.03 & 91.93 \\
\hline 3015 & 4.18 & 46.14 & 10.00 & 0.22 & 67.71 \\
\hline 3016 & 12.42 & 141.53 & 211.83 & 1.50 & 501.87 \\
\hline 3017 & 8.25 & 1218.56 & 11.92 & 0.01 & 30.19 \\
\hline 3018 & 0.68 & 400.82 & 9.06 & 0.02 & 15.64 \\
\hline 3019 & - & - - & - & - - & - \\
\hline 3020 & 0.96 & 107.07 & 10.46 & 0.10 & 62.27 \\
\hline 3021 & 2.16 & 133.97 & 5.33 & 0.04 & 15.90 \\
\hline 3022 & 8.26 & 601.64 & 119.98 & 0.20 & 195.81 \\
\hline 3023 & 2.86 & 67.88 & 42.20 & 0.62 & 68.99 \\
\hline 3024 & 6.23 & 526.07 & 75.11 & 0.14 & 131.08 \\
\hline 3025 & 5.89 & 368.46 & 59.61 & 0.16 & 117.89 \\
\hline 3026 & 2.95 & 304.54 & 3.80 & 0.01 & 5.16 \\
\hline 3027 & 6.00 & 255.54 & 50.20 & 0.20 & 116.07 \\
\hline 3028 & 1.16 & 180.72 & 6.88 & 0.04 & 17.66 \\
\hline 3029 & - - & - - & - & - & - \\
\hline 3030 & 1.14 & 92.76 & 3.86 & 0.04 & 8.58 \\
\hline 3031 & 1.45 & 37.16 & 5.95 & 0.16 & 19.82 \\
\hline 3032 & 12.35 & 617.28 & 78.87 & 0.13 & 105.18 \\
\hline 3033 & 2.64 & 150.25 & 57.84 & 0.38 & 155.93 \\
\hline 3034 & 3.78 & 345.90 & 37.97 & 0.11 & 71.87 \\
\hline 3035 & 11.14 & 2226.50 & 192.27 & 0.09 & 136.57 \\
\hline 3036 & 9.64 & 131.63 & 102.70 & 0.78 & 192.10 \\
\hline 3037 & 3.87 & 119.97 & 73.18 & 0.61 & 365.73 \\
\hline 3038 & - & - & - & - - & - \\
\hline
\end{tabular}

*The first digit of the code represents DHQase catalyzes the 3rd step of shikimate pathway, and the following digits are the order when that DHQase was selected. **Specific activities were determined at substrate concentration of 0.5 mM. "-" indicated no activity was detected.

\section{Discussion}

Kinetic diversity of enzymes is the results of natural revolution in life, similar to their phylogenetic diversity (Zhi et al. 2014). But the kinetic diversity of enzymes had not yet been explored before. This study took
DHQase as an example to explore the kinetic diversity of enzymes involved in shikimate pathway. The results from this study demonstrated that DHQases from various hosts had very broad ranges of affinity $\left(\mathrm{K}_{\mathrm{m}}\right)$ to substrate, catalytic efficiency and catalytic capacity $\left(k_{\text {cat }}\right.$ 


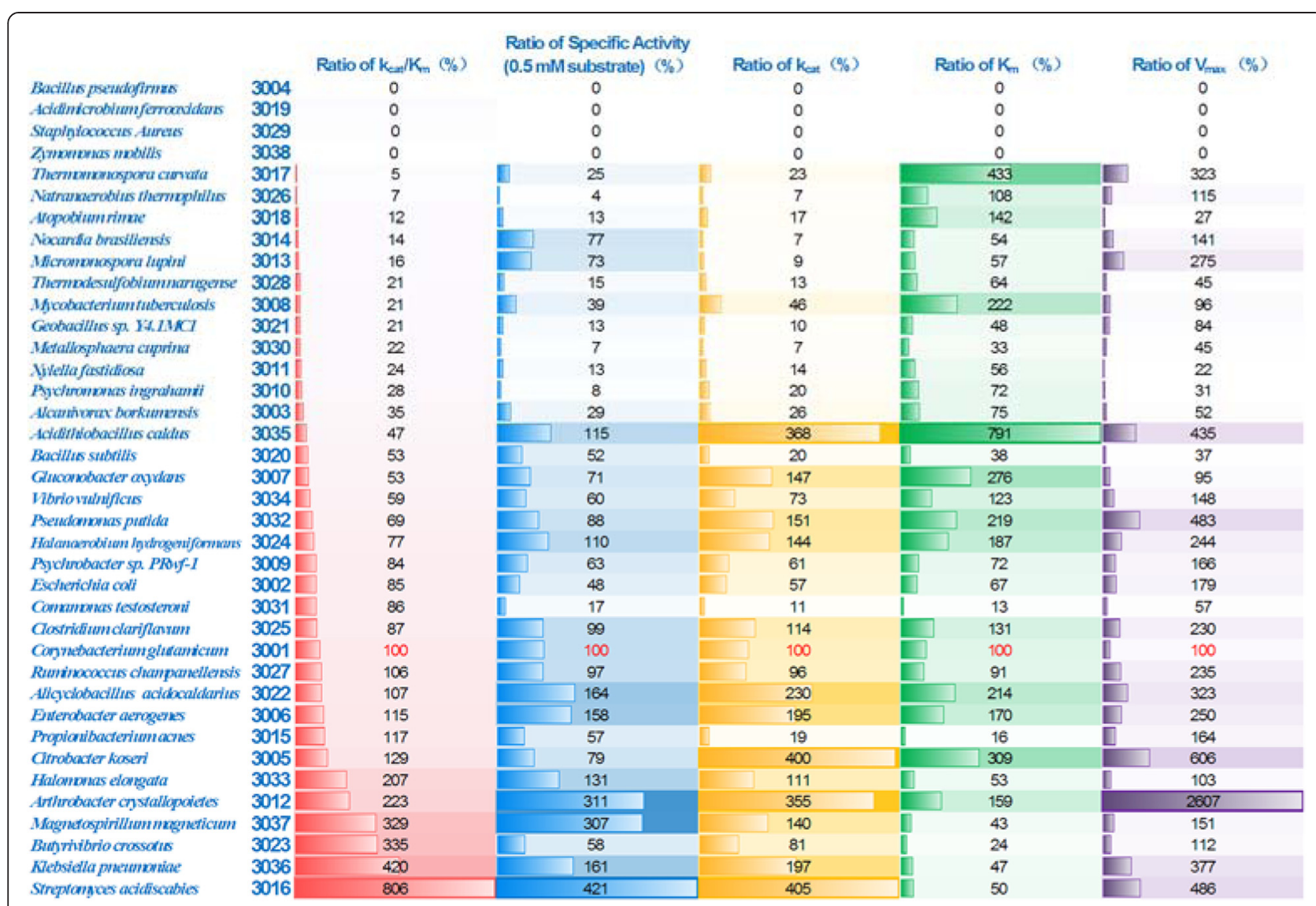

Figure 2 Demonstration of kinetic diversity of DHQases. Kinetic parameters were shown as ratio (in \%) of value of any DHQase to that of code 3001 . Four sets of kinetic parameters were displayed with color gradients.

and $\left.\mathrm{V}_{\max }\right)$. It was considered that other enzymes of the shikimate pathway would also have broad ranges of kinetic constants. Such broad ranges of kinetic constants are reflections of natural evolution and adaptation of enzymes, and founded the cornerstones of diverse metabolic fluxes in different lives. Therefore, it would be theoretically feasible to engineer metabolic processes quantitatively by mining enzymatic kinetic database. Such strategy is basically different from the current used strategy, ie., manipulation at levels of genetic transcription and translation (Rytter et al. 2014; Salis et al. 2009; Sohoni et al. 2014).

Recently, synthetic biology has emerged as a new discipline to manipulate biological systems for application and to understand the law of life (Andrianantoandro et al. 2006; Cheng and Lu 2012). The basic units for synthetic biology are standardized biological modules and parts, and standardized enzymes serve as catalytic parts for assembling novel and artificially designed biological systems (Cooling et al. 2010). Such catalytic part library is represented by the chemically synthesized genes of methyl halide transferases (Bayer et al. 2009). In this study, 38 selected DHQase genes were chemically synthesized and customized as Biobricks for future applications. All DHQases have Biobrick adapters, so they are compatible to other Biobrick parts/modules. Our study is part of an on-going project of design and construction of artificial modules for shikimate pathway using synthetic biological tools, aiming to create modules for shikimate pathway that would stimulate industrial applications for bioproduction of aromatic-related primary and secondary compounds. The pipeline for DHQase sequence design, chemical synthesis and purification established from this study has been generalized for other enzymes of the shikimate pathway, and construction of a catalytic part library of shikimate pathway is in progress.

Previous reports described that type I DHQases are represented by DHQases from plants and fungi (Hawkins et al. 1993; Weaver and Herrmann 1997), we have found that all 43 archaeal DHQases in this study were belonging to type I, although this study was focused on type II DHQases. Type II DHQases had been classified into two groups in terms of their kinetic constants $k_{\text {cat }}$ (Pan et al. 2012). The first group included DHQase from S. coelicolor and had relative high $\mathrm{k}_{\text {cat }}$ values larger than $100 \mathrm{~s}^{-1}$, whereas the sencond group 
included DHQase from M. tuberculosis with a $\mathrm{k}_{\mathrm{cat}}$ lower than $10 \mathrm{~s}^{-1}$. As demonstrated in this study, the $\mathrm{k}_{\text {cat }}$ values of DHQases distributed contineouslyfrom 4 to over $200 \mathrm{~s}^{-1}$, which rendered it unrealistic to devide them into two groups based on $\mathrm{k}_{\mathrm{cat}}$ values.

Alignments of type II DHQases revealed a number of conserved amino acid residues that are potentially important for catalytic efficiency and capacity. Specifically, the Tyr24 residue facilitated the proton abstraction from substrate, and then the His101 residues promoted the dehydrogenation by donating proton to 1-hydroxyl on $\mathrm{C} 1$ of substrate as a general acid (Blomberg et al. 2009; Pan et al. 2012). The residue His101was found in all the type II DHQases. But Tyr24 was replaced by Phe residue in DHQase from B. subtilis (Code 3020) (Data not shown). It was found that this DHQase (Code 3020) were functional and catalyzed the conversion of DHQ to 2-dehydroshikimate. The Phe residue was found in eighteen $B$. subtilis genomes as well as other bacilli genomes such as $B$. mojavensis, $B$. tequilensis, $B$. vallismortis, $B$. atrophaeus, demonstrating a natural evolution of Tyr24 into a Phe24 residue in members of the genus $B a-$ cillus. This natural evolution resulted in a low efficient but still active DHQase, which might be a result of adaption to the in vivo metabolic fluxes of bacilli cells. The catalytic mechanism of the Phe-DHQase has not been explored. Since Phe residue is rather stable and hard to be deprotonated, the catalytic mechanism of the PheDHQases might be different from that of the previous characterized DHQases.

\section{Competing interests}

The authors declare that they have no competing interests.

\section{Authors' contributions}

$\mathrm{CL}$ carried out the studies of gene cloning and expression, enzyme purification and activity determination. YL carried out the sequence analysis, gene recoding and participated gene cloning and expression, enzyme purification and activity determination. QLS carried out genome data mining and participated sequence analysis. Both CYJ and CL helped to draft the manuscript. SJL conceived of the study and finalized the manuscript. All authors read and approved the final manuscript.

\section{Acknowledgements}

This work was supported by 973 Project from Ministry of Science and Technology (No. 2012CB7211-04).

\section{Author details}

${ }^{1}$ State Key Laboratory of Microbial Resources, Chinese Academy of Sciences, Beijing 100101, China. ${ }^{2}$ Environmental Microbiology Research Center, Chinese Academy of Sciences, Beijing 100101, China. ${ }^{3}$ Bioinformatic Center at Institute of Microbiology, Chinese Academy of Sciences, Beijing 100101, China.

Received: 29 November 2014 Accepted: 17 December 2014 Published online: 01 February 2015

\section{References}

Abdennadher N, Boesch R (2007) Deploying PHYLIP phylogenetic package on a large scale distributed system. Paper presented at the CCGrid 2007: Seventh IEEE International Symposium on Cluster Computing and the Grid
Andrianantoandro E, Basu S, Karig DK, Weiss R (2006) Synthetic biology: new engineering rules for an emerging discipline. Mol Syst Biol doi:10.1038/ msb4100073

Bayer TS, Widmaier DM, Temme K, Mirsky EA, Santi DV, Voigt CA (2009) Synthesis of methyl halides from biomass using engineered microbes. J Am Chem Soc 131:6508-6515

Blanco B, Sedes A, Peon A, Lamb H, Hawkins AR, Castedo L, Gonzalez-Bello C (2012) Synthesis of 3-alkyl enol mimics inhibitors of type II dehydroquinase: factors influencing their inhibition potency. Org Biomol Chem 10:3662-3676

Blanco B, Sedes A, Peon A, Otero JM, van Raaij MJ, Thompson P, Hawkins AR, Gonzalez-Bello C (2014) Exploring the water-binding pocket of the type II dehydroquinase enzyme in the structure-based design of inhibitors. J Med Chem 57:3494-3510

Blomberg LM, Mangold M, Mitchell JBO, Blumberger J (2009) Theoretical study of the reaction mechanism of Streptomyces coelicolor Type II dehydroquinase. J Chem Theory Comput 5:1284-1294

Bottomley JR, Hawkins AR, Kleanthous C (1996) Conformational changes and the role of metals in the mechanism of type II dehydroquinase from Aspergillus nidulans. Biochem J J319:269-278

Chaudhuri S, Lambert JM, McColl LA, Coggins JR (1986) Purification and characterization of 3-dehydroquinase from Escherichia coli. Biogeosciences J239:699-704

Chaudhuri S, Duncan K, Graham LD, Coggins JR (1991) Identification of the active-site lysine residues of two biosynthetic 3-dehydroquinases. Biogeosciences J275:1-6

Cheng AA, Lu TK (2012) Synthetic biology: an emerging engineering discipline. Annu Rev Biomed Eng 14:155-178

Cooling MT, Rouilly V, Misirli G, Lawson J, Yu T, Hallinan J, Wipat A (2010) Standard virtual biological parts: a repository of modular modeling components for synthetic biology. Bioinformatics 26:925-931

Deka RK, Anton IA, Dunbar B, Coggins JR (1994) The Characterization of the shikimate pathway enzyme dehydroquinase from Pisum sativum. FEBS Lett 349:397-402

Devi AS, Ebihara A, Kuramitsu S, Yokoyama S, Kumarevel T, Ponnuraj K (2013) Crystal structure of type I 3-dehydroquinate dehydratase of Aquifex aeolicus suggests closing of active site flap is not essential for enzyme action. Biochem Biophys Res Commun 432:350-354

Dias MVB, Snee WC, Bromfield KM, Payne RJ, Palaninathan SK, Ciulli A, Howard NI, Abell C, Sacchettini JC, Blundell TL (2011) Structural investigation of inhibitor designs targeting 3-dehydroquinate dehydratase from the shikimate pathway of Mycobacterium tuberculosis. Biochem J 436:729-739

Edgar RC (2004) MUSCLE: a multiple sequence alignment method with reduced time and space complexity. BMC Bioinforma 5:1-19

Euverink GJW, Hessels Gl, Vrijbloed JW, Coggins JR, Dijkhuizen L (1992) Purification and characterization of a dual function 3-dehydroquinate dehydratase from Amycolatopsis methanolica. J Gen Microbiol 138:2449-2457

Giles NH, Case ME, Baum J, Geever R, Huiet L, Patel V, Tyler B (1985) Gene organization and regulation in the Qa (Quinic acid) gene-cluster of Neurospora crassa. Microbiol Rev 49:338-358

Giles NH, Geever RF, Asch DK, Avalos J, Case ME (1991) Organization and regulation of the Qa (Quinic acid) genes in Neurospora crassa and other fungi. J Hered 82:1-7

Gouet P, Courcelle E, Stuart DI, Metoz F (1999) ESPript: analysis of multiple sequence alignments in PostScript. Bioinformatics 15:305-308

Gourley DG, Shrive AK, Polikarpov I, Krell T, Coggins JR, Hawkins AR, Isaacs NW, Sawyer $L$ (1999) The two types of 3-dehydroquinase have distinct structures but catalyze the same overall reaction. Nat Struct Biol 6:521-525

Harris JM, GonzalezBello C, Kleanthous C, Hawkins AR, Coggins JR, Abell C (1996) Evidence from kinetic isotope studies for an enolate intermediate in the mechanism of type II dehydroquinases. Biogeosciences J319:333-336

Hawkins AR, Lamb HK, Moore JD, Charles IG, Roberts CF (1993) The pre-chorismate (shikimate) and quinate pathways in filamentous fungi - theoretical and practical aspects. J Gen Microbiol 139:2891-2899

Herrmann KM, Weaver LM (1999) The shikimate pathway. Annu Rev Plant Phys 50:473-503

Kleanthous C, Deka R, Davis K, Kelly SM, Cooper A, Harding SE, Price NC, Hawkins AR, Coggins JR (1992) A comparison of the enzymological and biophysical properties of two distinct classes of dehydroquinase enzymes. Biochem J J282:687-695

Knight TF (2003) Idempotent vector design for standard assembly of Biobricks. http://hdl.handle.net/1721.1/21168

Lee WH, Perles LA, Nagem RA, Shrive AK, Hawkins A, Sawyer L, Polikarpov I (2002) Comparison of different crystal forms of 3-dehydroquinase from 
Salmonella typhi and its implication for the enzyme activity. Acta Crystallogr D Biol Crystallogr 58:798-804

Lee BI, Kwak JE, Suh SW (2003) Crystal structure of the type II 3-dehydroquinase from Helicobacter pylori. Proteins 51:616-617

Leech AP, James R, Coggins JR, Kleanthous C (1995) Mutagenesis of active-site residues in Type-I dehydroquinase from Escherichia coli - stalled catalysis in a histidine to alanine mutant. J Biol Chem 270:25827-25836

Letunic I, Bork P (2011) Interactive tree of life v2: online annotation and display of phylogenetic trees made easy. Nucleic Acids Res 39:475-478

Markham NR, Zuker M (2008) UNAFold: software for nucleic acid folding and hybridization. Methods Mol Biol 453:3-31

Moore JD, Hawkins AR, Charles IG, Deka R, Coggins JR, Cooper A, Kelly SM, Price NC (1993) Characterization of the Type-I dehydroquinase from Salmonella typhi. Biogeosciences J295:277-285

Nakamura Y (2007) Condon usage database. http://www.kazusa.or.jp/codon/

Nishikura-Imamura S, Matsutani M, Insomphun C, Vangnai AS, Toyama H, Yakushi T, Abe T, Adachi O, Matsushita K (2014) Overexpression of a type II 3-dehydroquinate dehydratase enhances the biotransformation of quinate to 3-dehydroshikimate in Gluconobacter oxydans. Appl Microbiol Biotechnol 98:2955-2963

Pan Q, Yao Y, Li ZS (2012) Theoretical study of the reaction mechanism of Mycobacterium tuberculosis type II dehydroquinate dehydratase. Comput Theor Chem 1001:60-66

Peon A, Otero JM, Tizon L, Prazeres VFV, Llamas-Saiz AL, Fox GC, van Raaij MJ, Lamb H, Hawkins AR, Gago F, Castedo L, Gonzalez-Bello C (2010) Understanding the key factors that control the inhibition of Type II dehydroquinase by (2R)-2benzyl-3-dehydroquinic acids. ChemMedChem 5:1726-1733

Richards TA, Dacks JB, Campbell SA, Blanchard JL, Foster PG, McLeod R, Roberts CW (2006) Evolutionary origins of the eukaryotic shikimate pathway: gene fusions, horizontal gene transfer, and endosymbiotic replacements. Eukaryot Cell 5:1517-1531

Roszak AW, Robinson DA, Krell T, Hunter IS, Fredrickson M, Abell C, Coggins JR, Lapthorn AJ (2002) The structure and mechanism of the type II dehydroquinase from Streptomyces coelicolor. Structure 10:493-503

Rytter J, Helmark S, Chen J, Lezyk M, Solem C, Jensen P (2014) Synthetic promoter libraries for Corynebacterium glutamicum. Appl Microbiol Biotechnol 98:2617-2623

Salis HM, Mirsky EA, Voigt CA (2009) Automated design of synthetic ribosome binding sites to control protein expression. Nat Biotechnol 27:946-U112

Schägger H (2006) Tricine-SDS-PAGE. Nat Protoc 1:16-22

Shetty R, Lizarazo M, Rettberg R, Knight TF (2011) Assembly of biobrick standard biological parts using three antibiotic assembly. Methods Enzymol 498:311-326

Singh SA, Christendat D (2006) Structure of arabidopsis dehydroquinate dehydratase-shikimate dehydrogenase and implications for metabolic channeling in the shikimate pathway. Biochemistry 45:7787-7796

Sleight SC, Bartley BA, Lieviant JA, Sauro HM (2010) In-fusion BioBrick assembly and re-engineering. Nucleic Acids Res 38:2624-2636

Sohoni SV, Fazio A, Workman CT, Mijakovic I, Lantz E (2014) Synthetic promoter library for modulation of actinorhodin production in Streptomyces coelicolor A3(2). PLos ONE 9:e99701

Vanholme R, Storme V, Vanholme B, Sundin L, Christensen JH, Goeminne G, Halpin C, Rohde A, Morreel K, Boerjan W (2012) A systems biology view of responses to lignin biosynthesis perturbations in Arabidopsis. Plant Cell 24:3506-3529

Weaver LM, Herrmann KM (1997) Dynamics of the shikimate pathway in plants. Trends Plant Sci 2:346-351

White PJ, Young J, Hunter IS, Nimmo HG, Coggins JR (1990) The purification and characterization of 3-dehydroquinase from Streptomyces coelicolor. Biochem J 265:735-738

Zhi XY, Yao JC, Li HW, Huang Y, Li WJ (2014) Genome-wide identification, domain architectures and phylogenetic analysis provide new insights into the early evolution of shikimate pathway in prokaryotes. Mol Phylogenet Evol 75:154-164

\section{Submit your manuscript to a SpringerOpen ${ }^{\odot}$ journal and benefit from:}

- Convenient online submission

- Rigorous peer review

- Immediate publication on acceptance

- Open access: articles freely available online

- High visibility within the field

- Retaining the copyright to your article

Submit your next manuscript at $\gg$ springeropen.com 